\title{
Liver Development, Regeneration, and Carcinogenesis
}

\author{
Janet W. C. Kung, ${ }^{1}$ Ian S. Currie, ${ }^{1}$ Stuart J. Forbes, ${ }^{2}$ and James A. Ross ${ }^{1}$ \\ ${ }^{1}$ Tissue Injury and Repair Group, Medical Research Council Centre for Regenerative Medicine, \\ Chancellor's Building, 49 Little France Crescent, Edinburgh EH16 4SB, UK \\ ${ }^{2}$ Medical Research Council/University of Edinburgh Centre for Inflammation Research, \\ The Queen's Medical Research Institute, 47 Little France Crescent, Edinburgh EH16 4TJ, UK
}

Correspondence should be addressed to Janet W. C. Kung, janetkung@gmail.com

Received 6 September 2009; Accepted 12 November 2009

Academic Editor: David Colin Hay

Copyright (c) 2010 Janet W. C. Kung et al. This is an open access article distributed under the Creative Commons Attribution License, which permits unrestricted use, distribution, and reproduction in any medium, provided the original work is properly cited.

\begin{abstract}
The identification of putative liver stem cells has brought closer the previously separate fields of liver development, regeneration, and carcinogenesis. Significant overlaps in the regulation of these processes are now being described. For example, studies in embryonic liver development have already provided the basis for directed differentiation of human embryonic stem cells and induced pluripotent stem cells into hepatocyte-like cells. As a result, the understanding of the cell biology of proliferation and differentiation in the liver has been improved. This knowledge can be used to improve the function of hepatocyte-like cells for drug testing, bioartificial livers, and transplantation. In parallel, the mechanisms regulating cancer cell biology are now clearer, providing fertile soil for novel therapeutic approaches. Recognition of the relationships between development, regeneration, and carcinogenesis, and the increasing evidence for the role of stem cells in all of these areas, has sparked fresh enthusiasm in understanding the underlying molecular mechanisms and has led to new targeted therapies for liver cirrhosis and primary liver cancers.
\end{abstract}

\section{Introduction}

Worldwide, liver cancer is the fifth most common malignancy [1] and the third most common cause of cancer death [2]. Five hundred million individuals are infected with Hepatitis B or C and a proportion will progress to liver failure and cancer. As a result, the imperative to understand the mechanisms of liver disease and to improve treatments for liver disease has resulted in a dramatic expansion in liver research. Accordingly, this has driven forward the technical developments essential to the isolation, maintenance and propagation of highly purified cell subtypes which will underpin the therapies of the future. Better understanding of the physiology of liver development and the responses to liver injury has revealed emerging themes common to ontogeny, regeneration, and carcinogenesis. Regulatory pathways observed in one may form the basis for therapeutic intervention in another. This review describes recent insights into liver development, and the relationships with liver stem cells, hepatocyte proliferation, differentiation, and cancer. Potential therapeutic options are now emerging from our developing understanding of these pathways.

\section{Liver Development}

During embryonic development, totipotent stem cells of the blastocyst inner cell mass differentiate into multipotent tissue-specific progenitor cells. Fate-mapping experiments have shown that the liver arises from the lateral domains of endoderm in the ventral foregut $[3,4]$ and from a small group of cells tracking down the ventral midline [4]. During foregut closure, the medial and lateral domains fuse together and the endoderm cells are specified to a hepatic fate under the influence of inductive signals and genetic regulatory factors that are highly conserved among vertebrates. Studies in chick, frog, mouse, and zebrafish models indicate that coordinated signalling of fibroblast growth factors (FGF) from the cardiac mesoderm and 
bone morphogenetic proteins (BMP) from the septum transversum mesenchyme is critical in hepatic induction [5-9].

Following hepatic specification of the foregut endoderm, the cellular responses to inductive signals elicit new gene expression programmes required for cell differentiation. Wnt signalling, initially repressed by Wnt inhibitors to maintain foregut identity and allow hepatic induction [10, 11], becomes necessary to promote liver bud emergence and differentiation $[10,12,13]$. The newly specified hepatic cells, at this stage referred to as hepatoblasts, change to a columnar shape and invade the septum transversum mesenchyme to form the liver bud [14]. This transition involves coordinated interkinetic nuclear migration and proliferation, loss of intercellular adhesion, hepatoblast migration, and tissue-specific differentiation [15]. A number of studies in mutant mice have shown that liver bud formation is tightly controlled by a network of transcription factors, including haematopoetically expressed homeobox factor (Hex) [14, 16, 17], GATA-6 [18], hepatocyte nuclear factor (HNF)6 [19], Onecut (OC)-2 [19], T-box transcription factor 3 (Tbx3) [20], and prospero-related homeobox 1 (Prox-1) [21]. Once hepatoblasts bud into the local mesenchyme, they continue to proliferate under the influence of a variety of cytokines and growth factors secreted by mesenchymal cells in the septum transversum, such as FGF, epidermal growth factor (EGF), hepatocyte growth factor (HGF), transforming growth factor (TGF)- $\beta$, tumour necrosis factor (TNF)- $\alpha$, and interleukin-6 (IL-6) [22-25]. Stimulatory signals to hepatoblasts from neighbouring endothelial cells are of particular importance as the presence of endothelial cells, independent of the blood supply, is critical for normal liver organogenesis throughout development $[26,27]$. The specific molecular signals from endothelial cells are being studied; a recent study in the developing chick showed that Wnt9a secreted by the hepatic sinusoids not only stimulates hepatoblast proliferation, but it also controls global liver morphology [28, 29].

Hepatoblasts in the liver bud express serum protein genes specific to hepatocytes such as albumin (alb), transthyretin $(t t r)$, and $\alpha$-fetoprotein (afp) [30,31]. These cells are bipotential and soon after mesenchyme invasion differentiate into hepatocytes $\left(\alpha\right.$-fetoprotein ${ }^{+} /$albumin $\left.^{+}\right)$and cholangiocytes (cytokeratin $\left.(\mathrm{CK})-19^{+}\right)[5,32]$. The proper balance in the numbers of hepatocytes and cholangiocytes from hepatoblasts is achieved by integrated signalling and transcriptional networks. The Jagged-Notch pathway controls differentiation of hepatoblasts towards a biliary epithelial phenotype $[33,34]$, while HGF antagonises biliary differentiation and in conjunction with oncostatin M (OSM) promotes hepatocyte differentiation [35]. Following lineage segregation, the percentage of bipotent cells is markedly reduced and most cells are unipotent and irreversibly committed to either the hepatocytic or cholangiocytic lineage. Committed cells exhibit progressive change in morphology and physiologic functions, and this maturation process extends until several weeks after birth as demonstrated by a number of gene array analyses in rodent liver development [36-38]. An overview of embryonic liver development is presented in Figure 1.

\section{Stem/Progenitor Cells in Human Foetal Liver}

Studies in human liver development are relatively few in number as they rely heavily on ex vivo liver specimens. These studies are invaluable as not only do they provide direct observations and knowledge of the regulatory factors involved in human liver organogenesis but their findings could also lead to successful isolation and in vitro propagation of foetal liver progenitor cells suitable for clinical use. Human embryonic stem cells (ESCs) and induced pluripotent stem cells (iPSCs) hold great promise for a potentially abundant source of hepatocytes; however, directing their differentiation into specific, fully functional adult cell lineages remains a significant challenge. The use of foetal human liver progenitor cells abrogates the issue of forced differentiation, as foetal progenitors have undergone sufficient morphological and physiological differentiation so that they are committed to a hepatic fate, and yet they retain their "stemness" by maintaining their bipotentiality, proliferative capacity, and transplantability.

The phenotype of foetal human liver progenitor cells remains controversial. A range of cell markers based on rodent studies, such as Liv2 [39, 40], E-cadherin [41], and delta like kinase-1 (Dlk-1) [42], have only been characterised in human livers by immunodetection methods in vitro [43, 44]. To date, the only convincing evidence to show that liver progenitors can be isolated from human foetal livers comes from immunoselection for epithelial cell adhesion molecule (EpCAM)-positive cells [45]. In situ studies reveal that $\mathrm{EpCAM}^{+}$foetal liver progenitors are located in the ductal plate. Once isolated, these cells are capable of selfrenewal and clonogenic expansion, as well as differentiation into both hepatocytic and biliary lineages in defined culture conditions [45]. Moreover, purified $\mathrm{EpCAM}^{+}$foetal liver progenitors when transplanted are able to engraft the livers of immunodeficient adult mice yielding mature human liver tissue [45].

Another potential stem cell population, side population (SP) cells, has been found to contribute to haematopoietic and epithelial lineages in the early gestational phase of human liver development [46]. SP cells have been isolated using fluorescence-activated cell sorting based on their ability to efflux DNA-labelling Hoechst dye [47], a phenotype determined by expression of ATP-binding cassette (ABC) transporters encoded by the multidrug resistance (MDR)- 1 gene [46]. Their location in situ however remains uncertain, not least because of the widespread distribution of $A B C$ transporters in the liver [48]; clearly the vast majority of cells in the liver expressing $\mathrm{ABC}$ proteins are not stem cells [49].

\section{Translating Liver Development to Disease Models}

4.1. Liver Regeneration. The normal adult liver has considerable inherent regenerative capacity. Following acute liver injury, such as partial hepatectomy, the tissue mass is restored 


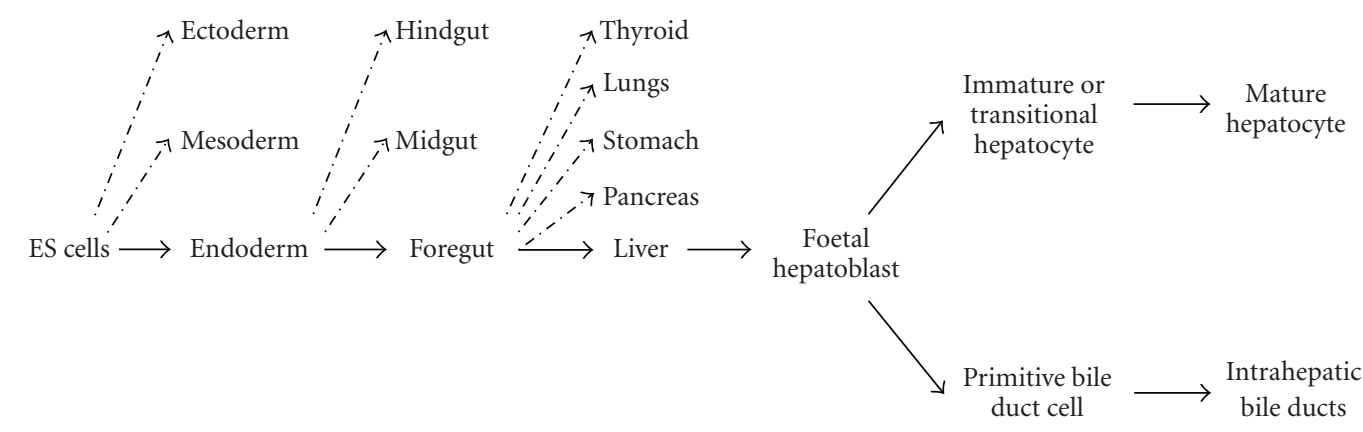

\begin{tabular}{|c|c|c|c|}
\hline & Specification & Budding & Differentiation \\
\hline \multicolumn{4}{|l|}{ Mouse } \\
\hline E3.5 & E7.5 & E13.5 & $14.5 \longrightarrow$ Postnat \\
\hline
\end{tabular}

Human

$\sim 2$ weeks $\sim 3$ weeks

$\sim 7$ weeks $\longrightarrow$ Postnatal

FIGURE 1: The lineage of the developing liver in vivo. Pluripotent embryonic stem (ES) cells from the blastocyst inner cell mass give rise to three principal germ layers: ectoderm, mesoderm, and endoderm. The anterior region of the endoderm will form the foregut. Following hepatic specification of foregut endoderm, hepatic cells (now called hepatoblasts) will bud into the septum transversum and continue to proliferate and differentiate. Maturation into hepatocytes and bile epithelial cells continue until several weeks after birth. The red bars highlight the key stages of liver development. The black bars in the middle are mouse embryos at different stages of development, and the blue bars at the bottom indicate the equivalent stages in human development.

by mitotic division of mature hepatocytes [50]. This division of mature hepatocytes provides an efficient means by which the normal liver can regain liver mass. The molecular signals underpinning this form of regeneration are now well understood (reviewed in [51]). However, this regenerative capacity is overwhelmed during massive or chronic injury and facultative liver progenitors (in rodents called oval cells) are activated. The two reparative processes are quite distinct yet not entirely mutually exclusive, as liver progenitors and hepatocyte replication can be observed simultaneously in some injury models $[52,53]$. Nonetheless, gene ontology analysis shows that restoration after hepatectomy and liver development differ significantly with regards to transcription factors and chromatin structure modification [54].

On the contrary, although the exact mechanisms controlling progenitor activation in chronic liver injury remain elusive, collective data suggest that in progenitor-mediated regeneration of the adult liver, the molecular signals may follow a pattern suggestive of a recapitulation of foetal development. Whilst undoubtedly simplistic, this helps provide a framework to understand the adult response, though unequivocally this will not be a complete parallel. First, $\mathrm{EpCAM}^{+}$cells purified from normal and injured adult human livers possess similar biological characteristics to those from foetal livers and function as bipotential progenitor cells $[45,55]$. Second, in situ antigenic profiling shows that $\mathrm{EpCAM}^{+}$progenitor cells are located at the canals of Hering, adult remnants of the ductal plates [55]. The progenitor nature of cells at the canals of Hering is further supported by a recent lineage tracing experiment [56]. Third, the same cytokines and growth factors involved in foetal development are also implicated in adult regeneration (reviewed in [57]). In rodent models of chronic liver injury, HGF [58-60] and EGF $[58,61]$ upregulate proliferation and expansion of oval cells while TGF- $\beta$ [62] and OSM [63] have the opposite effect. Fourth, upregulation of the Wnt/ $\beta$ catenin pathway in rodent models of both acute chemical [64] and chronic [65] liver injuries suggest symmetry between foetal development and adult regeneration at the transcription level. Taken together, adult liver regeneration parallels foetal development and involves progenitor cells that can be identified by anatomic, antigenic, and biochemical profiles.

It is evident that knowledge of the developmental biology of the liver provides clues to the molecular mechanisms in liver regeneration. This is critical in the search for a cure for chronic liver disease as specific pathways may be selectively targeted via pharmacological means to manipulate the progenitor cell compartment in adult liver. This has already been proven to be feasible with imatinib mesylate, a tyrosine kinase inhibitor, which has been shown to inhibit the liver progenitor cell response, liver fibrosis, and liver cancer formation in a mouse model of chronic liver injury [66]. Alternatively, this method of progenitor manipulation may be used to enhance liver regeneration in situ without the complications of cell engraftment and immunological rejection associated with transplantation. Further, efforts in programming human ESCs and iPSCs 
to generate hepatocytes de novo (reviewed in $[67,68]$ ) are founded on understanding how hepatocytes normally develop and differentiate in the embryo and how hepatocytes arise during regeneration in adults, in response to tissue damage and disease. The precise conditions that exist within the embryo which promote the differentiation of hepatocytes from pluripotent stem cells can be mimicked in vitro, for example, by using extracellular factors and recruiting accessory cell types to yield highly functional derivatives for drug screening, human bioartificial liver construction and, potentially, transplantation therapy.

4.2. Liver Stem Cells and Cancer. In the UK, the incidence of primary liver cancer has tripled in the last 30 years, and the associated mortality has increased by $40 \%$ over the last decade. Most worryingly, provisional data for 2008 indicate that the number of deaths from primary liver cancer is accelerating, with a $9 \%$ increase over the previous 12 months [69]. Given these statistics, there is an urgent need to understand the mechanisms of carcinogenesis in the liver and thereby aid the development of new forms of cancer therapy.

The cellular origin of HCC has long been debated, but whether HCC originates from mature hepatocytes, stem/progenitor cells, or both remain unclear. The fact that many liver tumours arise during cirrhosis when hepatocyte senescence triggers the activation of liver progenitors causes further confusion [70]. In the liver, there may be at least three distinct cell lineages susceptible to neoplastic transformation: hepatocytes, intrahepatic stem cells, or small hepatocytes [71, 72]. Most well-differentiated HCCs in the early stages are detected as small nodules with normal levels of AFP. Subsequently, they increase in size and become moderately or poorly differentiated cancerous tissues producing AFP [73]. This suggests that HCC might arise due to dedifferentiation of mature hepatocytes that have retained their ability to divide [74]. In addition, it is now accepted that the arrested differentiation of tissuebased stem cells or their immediate progenitors, the concept of blocked ontogeny, is linked to hepatocarcinogenesis [7577]. It has been suggested that intrahepatic stem cells can give rise to HCC and cholangiocarcinoma (CC) [78], as activation of oval cells has been demonstrated in rodent models of HCC and CC [79, 80]. Further, the role of intrahepatic stem cells in carcinogenesis is supported by a histological subtype of liver malignancies that displays features of both HCC and CC (HC-CC) combined with the presence of numerous liver progenitor cells $[81,82]$. The development of $\mathrm{HC}$-CC in mice implanted with p53-null oval cells suggests that dysregulated propagation of liver progenitors is an important early step in hepatocarcinogenesis [83].

There are several lines of evidence to suggest that hepatocarcinogenesis in part recapitulates foetal liver development, as both cell types have the capacity to self-renew, produce heterogeneous progeny, and divide limitlessly. First, hepatoblastomas presenting in their less differentiated phenotype in the livers of human infants represent an early stage in the cellular lineage pathway observed in the development of highly differentiated HCCs seen in adults, thereby supporting the progenitor cell differentiation arrest model [72]. Second, SP cells, which have hepatocytic and cholangiocytic potential in foetal livers, have been isolated in a number of HCC cell lines and are capable of tumour formation with a starting population of as few as $10^{3}$ cells in serial xenotransplantation experiments [84]. Third, foetal liver progenitors and HCC cell lines share a number of oncofetal markers. A recent study has shown that Huh1, Huh7, and Hep3B cell lines all express EpCAM to varying degrees, with up to $99.2 \%$ of Hep3B cells being EpCAM ${ }^{+}$[85]. Purified EpCAM ${ }^{+}$cells from HCC cell lines and human clinical specimens possess progenitor features and, when injected into immunodeficient adult mice, exhibit tumorigenic and invasive capacity $[85,86]$. Moreover, individuals with HCC whose gene expression profiles match that of foetal hepatoblasts have a poorer prognosis compared to those with adult genomic profiles $[82,86]$. Fourth, signalling mechanisms central to embryonic liver development have been implicated in hepatocarcinogenesis. Activation of $\mathrm{Wnt} / \beta$-catenin signalling is observed in $\mathrm{OV}^{+}$ HCC cells in rats [87] and EpCAM ${ }^{+}$HCC cells in humans [88] and is linked to their excessive self-renewal capability and tumorigenicity. Aberrant TGF- $\beta$ and IL- 6 signalling has also been found to promote the growth of stem/progenitor cells in their undifferentiated state and contributes to the modulation of HCC [89].

In recognition of the symmetry between liver development and carcinogenesis and the possible role of liver cancer stem cells, new approaches to the treatment of primary liver cancer have been proposed. The inhibition of specific molecular pathways is one promising strategy. A recent study has shown that $\mathrm{Hep} 3 \mathrm{~B}$ cell growth can be inhibited by RNA interference-based blockage of EpCAM, a direct transcriptional target of $\mathrm{Wnt} / \beta$-catenin signaling [85]. Encouragingly, EpCAM-specific antibodies, though not licensed for treating HCC, are currently in phase II clinical trials for the treatment of $\mathrm{EpCAM}^{+}$colorectal carcinoma [90]. An alternative strategy is differentiation therapy, whereby liver cancer stem cells are induced to differentiate and in so doing lose their self-renewal capacity and tumorigenic potential. In transgenic mice in which the c-Myc oncogene is inactivated, tumorigenesis is reversed with HCC cells losing their neoplastic properties and differentiating into hepatocytes and biliary cells [91]. It is also conceivable that the fate of liver progenitors may be manipulated by targeting the stem cell niche, as the specified microenvironment in which stem cells reside often dictates self-renewal and differentiation [92]. One potentially effective target is endothelial cells, as not only are they a critical component of the liver progenitor cell niche but they are responsible for neovascularisation which is a crucial prerequisite for hepatocarcinogenesis $[93,94]$. A number of anti-angiogenic agents, namely, bevacizumab, erlotinib, and sorafenib, have already entered clinical trials for HCC and shown efficacy in some instances $[95,96]$. Although these agents hold much promise, their effect on the improvement in overall survival is still marginal $[95,96]$. There is no doubt that much more research on the microenvironment supportive for HCC progression is urgently needed. 


\section{Conclusion}

There are common threads which span liver development, regeneration and carcinogenesis, notably the cellular functional phenotype responsible for each process and the molecular machinery dictating appropriate cell fate. The identification of stem cell candidates in the developing liver, and cancer stem cells in liver tumours, has revealed physiological themes relating to surface markers and the regulation of proliferation and differentiation. Further progress towards the clinical application of stem cells and ES-derived liver cells is critically dependent on detailed understanding of all of these mechanisms. Only when the generation of nontumorigenic cells for liver therapy and the interactions of these cells with host tissues are understood, can the promise of liver stem cell therapy be fully realised in human liver disease.

\section{Acknowledgment}

This work was supported by a Medical Research Council/Royal College of Surgeons of Edinburgh Clinical Research Training Fellowship.

\section{References}

[1] A. Jemal, R. Siegel, E. Ward, et al., "Cancer statistics, 2008," CA: A Cancer Journal for Clinicians, vol. 58, no. 2, pp. 71-96, 2008.

[2] D. M. Parkin, F. Bray, J. Ferlay, and P. Pisani, "Global cancer statistics, 2002," CA: A Cancer Journal for Clinicians, vol. 55, no. 2, pp. 74-108, 2005.

[3] A. D. Chalmers and J. M. W. Slack, "The Xenopus tadpole gut: fate maps and morphogenetic movements," Development, vol. 127, no. 2, pp. 381-392, 2000.

[4] K. D. Tremblay and K. S. Zaret, "Distinct populations of endoderm cells converge to generate the embryonic liver bud and ventral foregut tissues," Developmental Biology, vol. 280, no. 1, pp. 87-99, 2005.

[5] J. Jung, M. Zheng, M. Goldfarb, and K. S. Zaret, "Initiation of mammalian liver development from endoderm by fibroblast growth factors," Science, vol. 284, no. 5422, pp. 1998-2003, 1999.

[6] J. M. Rossi, N. R. Dunn, B. L. M. Hogan, and K. S. Zaret, "Distinct mesodermal signals, including BMPs from the septum, transversum mesenchyme, are required in combination for hepatogenesis from the endoderm," Genes and Development, vol. 15, no. 15, pp. 1998-2009, 2001.

[7] G. Deutsch, J. Jung, M. Zheng, J. Lóra, and K. S. Zaret, "A bipotential precursor population for pancreas and liver within the embryonic endoderm," Development, vol. 128, no. 6, pp. 871-881, 2001.

[8] D. Shin, C. H. Shin, J. Tucker, et al., "Bmp and Fgf signaling are essential for liver specification in zebrafish," Development, vol. 134, no. 11, pp. 2041-2050, 2007.

[9] W. Zhang, T. A. Yatskievych, R. K. Baker, and P. B. Antin, "Regulation of Hex gene expression and initial stages of avian hepatogenesis by Bmp and Fgf signaling," Developmental Biology, vol. 268, no. 2, pp. 312-326, 2004.

[10] V. A. McLin, S. A. Rankin, and A. M. Zorn, "Repression of $\mathrm{Wnt} / \beta$-catenin signaling in the anterior endoderm is essential for liver and pancreas development," Development, vol. 134, no. 12, pp. 2207-2217, 2007.

[11] K. R. Finley, J. Tennessen, and W. Shawlot, "The mouse Secreted frizzled-related protein 5 gene is expressed in the anterior visceral endoderm and foregut endoderm during early post-implantation development," Gene Expression Patterns, vol. 3, no. 5, pp. 681-684, 2003.

[12] S. P. S. Monga, H. K. Monga, X. Tan, K. Mulé, P. Pediaditakis, and G. K. Michalopoulos, " $\beta$-catenin antisense studies in embryonic liver cultures: role in proliferation, apoptosis, and lineage specification," Gastroenterology, vol. 124, no. 1, pp. 202-216, 2003.

[13] E. A. Ober, H. Verkade, H. A. Field, and D. Y. Stainier, "Mesodermal Wnt2b signalling positively regulates liver specification," Nature, vol. 442, no. 7103, pp. 688-691, 2006.

[14] R. Bort, M. Signore, K. Tremblay, J. P. Martinez Barbera, and K. S. Zaret, "Hex homeobox gene controls the transition of the endoderm to a pseudostratified, cell emergent epithelium for liver bud development," Developmental Biology, vol. 290, no. 1, pp. 44-56, 2006.

[15] F. P. Lemaigre, "Mechanisms of liver development: concepts for understanding liver disorders and design of novel therapies," Gastroenterology, vol. 137, no. 1, pp. 62-79, 2009.

[16] J. P. Martinez Barbera, M. Clements, P. Thomas, et al., "The homeobox gene Hex is required in definitive endodermal tissues for normal forebrain, liver and thyroid formation," Development, vol. 127, no. 11, pp. 2433-2445, 2000.

[17] V. W. Keng, H. Yagi, M. Ikawa, et al., "Homeobox gene Hex is essential for onset of mouse embryonic liver development and differentiation of the monocyte lineage," Biochemical and Biophysical Research Communications, vol. 276, no. 3, pp. 1155-1161, 2000.

[18] R. Zhao, A. J. Watt, J. Li, J. Luebke-Wheeler, E. E. Morrisey, and S. A. Duncan, "GATA6 is essential for embryonic development of the liver but dispensable for early heart formation," Molecular and Cellular Biology, vol. 25, no. 7, pp. 2622-2631, 2005.

[19] S. Margagliotti, F. Clotman, C. E. Pierreux, et al., "The Onecut transcription factors HNF-6/OC-1 and OC-2 regulate early liver expansion by controlling hepatoblast migration," Developmental Biology, vol. 311, no. 2, pp. 579-589, 2007.

[20] T. H.-W. Lüdtke, V. M. Christoffels, M. Petry, and A. Kispert, "Tbx3 promotes liver bud expansion during mouse development by suppression of cholangiocyte differentiation," Hepatology, vol. 49, no. 3, pp. 969-978, 2009.

[21] B. Sosa-Pineda, J. T. Wigle, and G. Oliver, "Hepatocyte migration during liver development requires Prox1," Nature Genetics, vol. 25, no. 3, pp. 254-255, 2000.

[22] C. Schmidt, F. Bladt, S. Goedecke, et al., "Scatter factor/hepatocyte growth factor is essential for liver development," Nature, vol. 373, no. 6516, pp. 699-702, 1995.

[23] N. Tanimizu and A. Miyajima, "Molecular mechanism of liver development and regeneration," International Review of Cytology, vol. 259, pp. 1-48, 2007.

[24] M. Weinstein, S. P. S. Monga, Y. Liu, et al., "Smad proteins and hepatocyte growth factor control parallel regulatory pathways that converge on $\beta 1$-integrin to promote normal liver development," Molecular and Cellular Biology, vol. 21, no. 15, pp. 5122-5131, 2001.

[25] R. Zhao and S. A. Duncan, "Embryonic development of the liver," Hepatology, vol. 41, no. 5, pp. 956-967, 2005.

[26] K. Matsumoto, H. Yoshitomi, J. Rossant, and K. S. Zaret, "Liver organogenesis promoted by endothelial cells prior to 
vascular function," Science, vol. 294, no. 5542, pp. 559-563, 2001.

[27] E. Lammert, O. Cleaver, and D. Melton, "Role of endothelial cells in early pancreas and liver development," Mechanisms of Development, vol. 120, no. 1, pp. 59-64, 2003.

[28] K. Matsumoto, R. Miki, M. Nakayama, N. Tatsumi, and Y. Yokouchi, "Wnt9a secreted from the walls of hepatic sinusoids is essential for morphogenesis, proliferation, and glycogen accumulation of chick hepatic epithelium," Developmental Biology, vol. 319, no. 2, pp. 234-247, 2008.

[29] S. Suksaweang, C.-M. Lin, T.-X. Jiang, M. W. Hughes, R. B. Widelitz, and C.-M. Chuong, "Morphogenesis of chicken liver: identification of localized growth zones and the role of $\beta$-catenin/Wnt in size regulation," Developmental Biology, vol. 266, no. 1, pp. 109-122, 2004.

[30] F. Lemaigre and K. S. Zaret, "Liver development update: new embryo models, cell lineage control, and morphogenesis," Current Opinion in Genetics and Development, vol. 14, no. 5, pp. 582-590, 2004.

[31] K. S. Zaret, "Genetic programming of liver and pancreas progenitors: lessons for stem-cell differentiation," Nature Reviews Genetics, vol. 9, no. 5, pp. 329-340, 2008.

[32] L. Germain, M.-J. Blouin, and N. Marceau, "Biliary epithelial and hepatocytic cell lineage relationships in embryonic rat liver as determined by the differential expression of cytokeratins, $\alpha$-fetoprotein, albumin, and cell surface-exposed components," Cancer Research, vol. 48, no. 17, pp. 4909-4918, 1988.

[33] B. McCright, J. Lozier, and T. Gridley, "A mouse model of Alagille syndrome: notch2 as a genetic modifier of Jag1 haploinsufficiency," Development, vol. 129, no. 4, pp. 10751082, 2002.

[34] N. Tanimizu and A. Miyajima, "Notch signaling controls hepatoblast differentiation by altering the expression of liverenriched transcription factors," Journal of Cell Science, vol. 117, no. 15, pp. 3165-3174, 2004.

[35] A. Suzuki, A. Iwana, H. Miyashita, H. Nakauchi, and H. Taniguchi, "Role for growth factors and extracellular matrix in controlling differentiation of prospectively isolated hepatic stem cells," Development, vol. 130, no. 11, pp. 2513-2524, 2003.

[36] A. Jochheim, A. Cieslak, T. Hillemann, et al., "Multi-stage analysis of differential gene expression in BALB/C mouse liver development by high-density microarrays," Differentiation, vol. 71, no. 1, pp. 62-72, 2003.

[37] N. Kelley-Loughnane, G. E. Sabla, C. Ley-Ebert, B. J. Aronow, and J. A. Bezerra, "Independent and overlapping transcriptional activation during liver development and regeneration in mice," Hepatology, vol. 35, no. 3, pp. 525-534, 2002.

[38] P. M. Petkov, J. Zavadil, D. Goetz, et al., "Gene expression pattern in hepatic stem/progenitor cells during rat fetal development using complementary DNA microarrays," Hepatology, vol. 39, no. 3, pp. 617-627, 2004.

[39] T. Watanabe, K. Nakagawa, S. Ohata, et al., "SEK1/MKK4mediated SAPK/JNK signaling participates in embryonic hepatoblast proliferation via a pathway different from NF- $\kappa$ Binduced anti-apoptosis," Developmental Biology, vol. 250, no. 2, pp. 332-347, 2002.

[40] I. Takashimizu, Y. Tanaka, S. Yoshie, et al., "Localization of Liv2 as an immature hepatocyte marker in EB outgrowth," The Scientific World Journal, vol. 9, pp. 190-199, 2009.

[41] M. Nitou, Y. Sugiyama, K. Ishikawa, and N. Shiojiri, "Purification of fetal mouse hepatoblasts by magnetic beads coated with monoclonal anti-E-cadherin antibodies and their in vitro culture," Experimental Cell Research, vol. 279, no. 2, pp. 330343, 2002.

[42] N. Tanimizu, M. Nishikawa, H. Saito, T. Tsujimura, and A. Miyajima, "Isolation of hepatoblasts based on the expression of Dlk/Pref-1," Journal of Cell Science, vol. 116, no. 9, pp. 17751786, 2003.

[43] M. Inada, D. Benten, K. Cheng, et al., "Stage-specific regulation of adhesion molecule expression segregates epithelial stem/progenitor cells in fetal and adult human livers," Нераtology International, vol. 2, no. 1, pp. 50-62, 2008.

[44] J. D. Terrace, I. S. Currie, D. C. Hay, et al., "Progenitor cell characterization and location in the developing human liver," Stem Cells and Development, vol. 16, no. 5, pp. 771-778, 2007.

[45] E. Schmelzer, L. Zhang, A. Bruce, et al., "Human hepatic stem cells from fetal and postnatal donors," Journal of Experimental Medicine, vol. 204, no. 8, pp. 1973-1987, 2007.

[46] J. D. Terrace, D. C. Hay, K. Samuel, et al., "Side population cells in developing human liver are primarily haematopoietic progenitor cells," Experimental Cell Research, vol. 315, no. 13, pp. 2141-2153, 2009.

[47] M. A. Goodell, S. McKinney-Freeman, and F. D. Camargo, "Isolation and characterization of side population cells," Methods in Molecular Biology, vol. 290, pp. 343-352, 2005.

[48] T. Plösch, A. Kosters, A. K. Groen, and F. Kuipers, "The ABC of hepatic and intestinal cholesterol transport," Handbook of Experimental Pharmacology, no. 170, pp. 465-482, 2005.

[49] S. J. Forbes and M. R. Alison, "Side population (SP) cells: taking center stage in regeneration and liver cancer?" Hepatology, vol. 44, no. 1, pp. 23-26, 2006.

[50] N. Fausto, J. S. Campbell, and K. J. Riehle, "Liver regeneration," Hepatology, vol. 43, no. 2, supplement 1, pp. 45-53, 2006.

[51] G. K. Michalopoulos and M. C. DeFrances, "Liver regeneration," Science, vol. 276, no. 5309, pp. 60-66, 1997.

[52] X. Wang, M. Foster, M. Al-Dhalimy, E. Lagasse, M. Finegold, and M. Grompe, "The origin and liver repopulating capacity of murine oval cells," Proceedings of the National Academy of Sciences of the United States of America, vol. 100, supplement 1, pp. 11881-11888, 2003.

[53] D. Rosenberg, Z. Ilic, L. I. Yin, and S. Sell, "Proliferation of hepatic lineage cells of normal C57BL and interleukin6 knockout mice after cocaine-induced periportal injury," Hepatology, vol. 31, no. 4, pp. 948-955, 2000.

[54] H. H. Otu, K. Naxerova, K. Ho, et al., "Restoration of liver mass after injury requires proliferative and not embryonic transcriptional patterns," Journal of Biological Chemistry, vol. 282, no. 15, pp. 11197-11204, 2007.

[55] L. Zhang, N. Theise, M. Chua, and L. M. Reid, "The stem cell niche of human livers: symmetry between development and regeneration," Hepatology, vol. 48, no. 5, pp. 1598-1607, 2008.

[56] T. G. Fellous, S. Islam, P. J. Tadrous, et al., "Locating the stem cell niche and tracing hepatocyte lineages in human liver," Hepatology, vol. 49, no. 5, pp. 1655-1663, 2009.

[57] T. G. Bird, S. Lorenzini, and S. J. Forbes, "Activation of stem cells in hepatic diseases," Cell and Tissue Research, vol. 331, no. 1, pp. 283-300, 2008.

[58] P. Nagy, H. C. Bisgaard, E. Santoni-Rugiu, and S. S. Thorgeirsson, "In vivo infusion of growth factors enhances the mitogenic response of rat hepatic ductal (oval) cells after administration of 2-acetylaminofluorene," Hepatology, vol. 23, no. 1, pp. 71-79, 1996. 
[59] S. Hasuike, A. Ido, H. Uto, et al., "Hepatocyte growth factor accelerates the proliferation of hepatic oval cells and possibly promotes the differentiation in a 2-acetylaminofluorene/partial hepatectomy model in rats," Journal of Gastroenterology and Hepatology, vol. 20, no. 11, pp. 1753-1761, 2005.

[60] H. Oe, T. Kaido, A. Mori, H. Onodera, and M. Imamura, "Hepatocyte growth factor as well as vascular endothelial growth factor gene induction effectively promotes liver regeneration after hepatectomy in Solt-Farber rats," HepatoGastroenterology, vol. 52, no. 65, pp. 1393-1397, 2005.

[61] R. J. Isfort, D. B. Cody, S. B. Stuard, et al., "The combination of epidermal growth factor and transforming growth factorbeta induces novel phenotypic changes in mouse liver stem cell lines," Journal of Cell Science, vol. 110, no. 24, pp. 3117-3129, 1997.

[62] L. N. Nguyen, M. H. Furuya, L. A. Wolfraim, et al., "Transforming growth factor-beta differentially regulates oval cell and hepatocyte proliferation," Hepatology, vol. 45, no. 1, pp. 31-41, 2007.

[63] V. B. Matthews, B. Knight, J. E. E. Tirnitz-Parker, J. Boon, J. K. Olynyk, and G. C. T. Yeoh, "Oncostatin M induces an acute phase response but does not modulate the growth or maturation-status of liver progenitor (oval) cells in culture," Experimental Cell Research, vol. 306, no. 1, pp. 252-263, 2005.

[64] U. Apte, S. Singh, G. Zeng, et al., "Beta-catenin activation promotes liver regeneration after acetaminophen-induced injury," American Journal of Pathology, vol. 175, no. 3, pp. 1056-1065, 2009.

[65] T. Itoh, Y. Kamiya, M. Okabe, M. Tanaka, and A. Miyajima, "Inducible expression of Wnt genes during adult hepatic stem/progenitor cell response," FEBS Letters, vol. 583, no. 4, pp. 777-781, 2009.

[66] B. Knight, J. E. E. Tirnitz-Parker, and J. K. Olynyk, "Ckit inhibition by imatinib mesylate attenuates progenitor cell expansion and inhibits liver tumor formation in mice," Gastroenterology, vol. 135, no. 3, pp. 969.e1-979.e1, 2008.

[67] T. C. McDevitt and S. P. Palecek, "Innovation in the culture and derivation of pluripotent human stem cells," Current Opinion in Biotechnology, vol. 19, no. 5, pp. 527-533, 2008.

[68] D. M. Dalgetty, C. N. Medine, J. P. Iredale, and D. C. Hay, "Progress and future challenges in stem cell-derived liver technologies," American Journal of Physiology, vol. 297, no. 2, pp. G241-G248, 2009.

[69] http://www.britishlivertrust.org.uk/modules/news/Story. Viewer.aspx?pid=6\&intextraid=2303\&fid $=2007$

[70] A. S. Befeler and A. M. Di Bisceglie, "Hepatocellular carcinoma: diagnosis and treatment," Gastroenterology, vol. 122, no. 6, pp. 1609-1619, 2002.

[71] S. Sell and H. L. Leffert, "An evaluation of cellular lineages in the pathogenesis of experimental hepatocellular carcinoma," Hepatology, vol. 2, no. 1, pp. 77-86, 1982.

[72] S. Sell and H. L. Leffert, "Liver cancer stem cells," Journal of Clinical Oncology, vol. 26, no. 17, pp. 2800-2805, 2008.

[73] T. Chiba, A. Kamiya, O. Yokosuka, and A. Iwama, "Cancer stem cells in hepatocellular carcinoma: recent progress and perspective," Cancer Letters, vol. 286, no. 2, pp. 145-153, 2009.

[74] K. Aterman, "Hepatic neoplasia: reflections and ruminations," Virchows Archiv, vol. 427, no. 1, pp. 1-18, 1995.

[75] V. R. Potter, "Recent trends in cancer biochemistry: the importance of studies on fetal tissue," in Proceedings of the 8th Canadian Cancer Conference, vol. 8, pp. 9-30, Ontario, Canada, 1969.
[76] V. R. Potter, "Phenotypic diversity in experimental hepatomas: the concept of partially blocked ontogeny," British Journal of Cancer, vol. 38, no. 1, pp. 1-23, 1978, The 10th Walter Hubert Lecture.

[77] V. R. Potter, "The present status of the blocked ontogeny hypothesis of neoplasia: the thalassemia connection," Oncodevelopmental Biology and Medicine, vol. 2, no. 4, pp. 243-266, 1981.

[78] M. R. Alison and M. J. Lovell, "Liver cancer: the role of stem cells," Cell Proliferation, vol. 38, no. 6, pp. 407-421, 2005.

[79] M. L. Dumble, E. J. Croager, G. C. T. Yeoh, and E. A. Quail, "Generation and characterization of p53 null transformed hepatic progenitor cells: oval cells give rise to hepatocellular carcinoma," Carcinogenesis, vol. 23, no. 3, pp. 435-445, 2002.

[80] P. Steinberg, R. Steinbrecher, S. Radaeva, et al., "Oval cell lines OC/CDE 6 and OC/CDE 22 give rise to cholangio-cellular and undifferentiated carcinomas after transformation," Laboratory Investigation, vol. 71, no. 5, pp. 700-709, 1994.

[81] N. D. Theise, J. L. Yao, K. Harada, et al., "Hepatic 'stem cell' malignancies in adults: four cases," Histopathology, vol. 43, no. 3, pp. 263-271, 2003.

[82] J.-S. Lee, J. Heo, L. Libbrecht, et al., "A novel prognostic subtype of human hepatocellular carcinoma derived from hepatic progenitor cells," Nature Medicine, vol. 12, no. 4, pp. 410-416, 2006.

[83] A. Suzuki, S. Sekiya, M. Onishi, et al., "Flow cytometric isolation and clonal identification of self-renewing bipotent hepatic progenitor cells in adult mouse liver," Hepatology, vol. 48, no. 6, pp. 1964-1978, 2008.

[84] T. Chiba, K. Kita, Y.-W. Zheng, et al., "Side population purified from hepatocellular carcinoma cells harbors cancer stem celllike properties," Hepatology, vol. 44, no. 1, pp. 240-251, 2006.

[85] T. Yamashita, J. Ji, A. Budhu, et al., "EpCAM-positive hepatocellular carcinoma cells are tumor-initiating cells with stem/progenitor cell features," Gastroenterology, vol. 136, no. 3, pp. 1012-1024, 2009.

[86] T. Yamashita, M. Forgues, W. Wang, et al., "EpCAM and $\alpha$ fetoprotein expression defines novel prognostic subtypes of hepatocellular carcinoma," Cancer Research, vol. 68, no. 5, pp. 1451-1461, 2008.

[87] W. Yang, H.-X. Yan, L. Chen, et al., "Wnt/ $\beta$-catenin signaling contributes to activation of normal and tumorigenic liver progenitor cells," Cancer Research, vol. 68, no. 11, pp. 42874295, 2008.

[88] T. Yamashita, A. Budhu, M. Forgues, and W. W. Xin, "Activation of hepatic stem cell marker EpCAM by Wnt- $\beta$-catenin signaling in hepatocellular carcinoma," Cancer Research, vol. 67, no. 22, pp. 10831-10839, 2007.

[89] Y. Tang, K. Kitisin, W. Jogunoori, et al., "Progenitor/stem cells give rise to liver cancer due to aberrant TGF- $\beta$ and IL6 signaling," Proceedings of the National Academy of Sciences of the United States of America, vol. 105, no. 7, pp. 2445-2450, 2008.

[90] M. A. Chaudry, K. Sales, P. Ruf, H. Lindhofer, and M. C. Winslet, "EpCAM an immunotherapeutic target for gastrointestinal malignancy: current experience and future challenges," British Journal of Cancer, vol. 96, no. 7, pp. 10131019, 2007.

[91] C. M. Shachaf, A. M. Kopelman, C. Arvanitis, et al., "MYC inactivation uncovers pluripotent differentiation and tumour dormancy in hepatocellular cancer," Nature, vol. 431, no. 7012, pp. 1112-1117, 2004. 
[92] L. Mishra, T. Banker, J. Murray, et al., "Liver stem cells and hepatocellular carcinoma," Hepatology, vol. 49, no. 1, pp. 318329, 2009.

[93] M. Kin, T. Torimura, T. Ueno, S. Inuzuka, and K. Tanikawa, "Sinusoidal capillarization in small hepatocellular carcinoma," Pathology International, vol. 44, no. 10-11, pp. 771-778, 1994.

[94] Y. N. Park, C.-P. Yang, G. J. Fernandez, O. Cubukcu, S. N. Thung, and N. D. Theise, "Neoangiogenesis and sinusoidal "capillarization " in dysplastic nodules of the liver," American Journal of Surgical Pathology, vol. 22, no. 6, pp. 656-662, 1998.

[95] M. B. Thomas, J. S. Morris, R. Chadha, et al., "Phase II trial of the combination of bevacizumab and erlotinib in patients who have advanced hepatocellular carcinoma," Journal of Clinical Oncology, vol. 27, no. 6, pp. 843-850, 2009.

[96] L. Rimassa and A. Santoro, "Sorafenib therapy in advanced hepatocellular carcinoma: the SHARP trial," Expert Review of Anticancer Therapy, vol. 9, no. 6, pp. 739-745, 2009. 

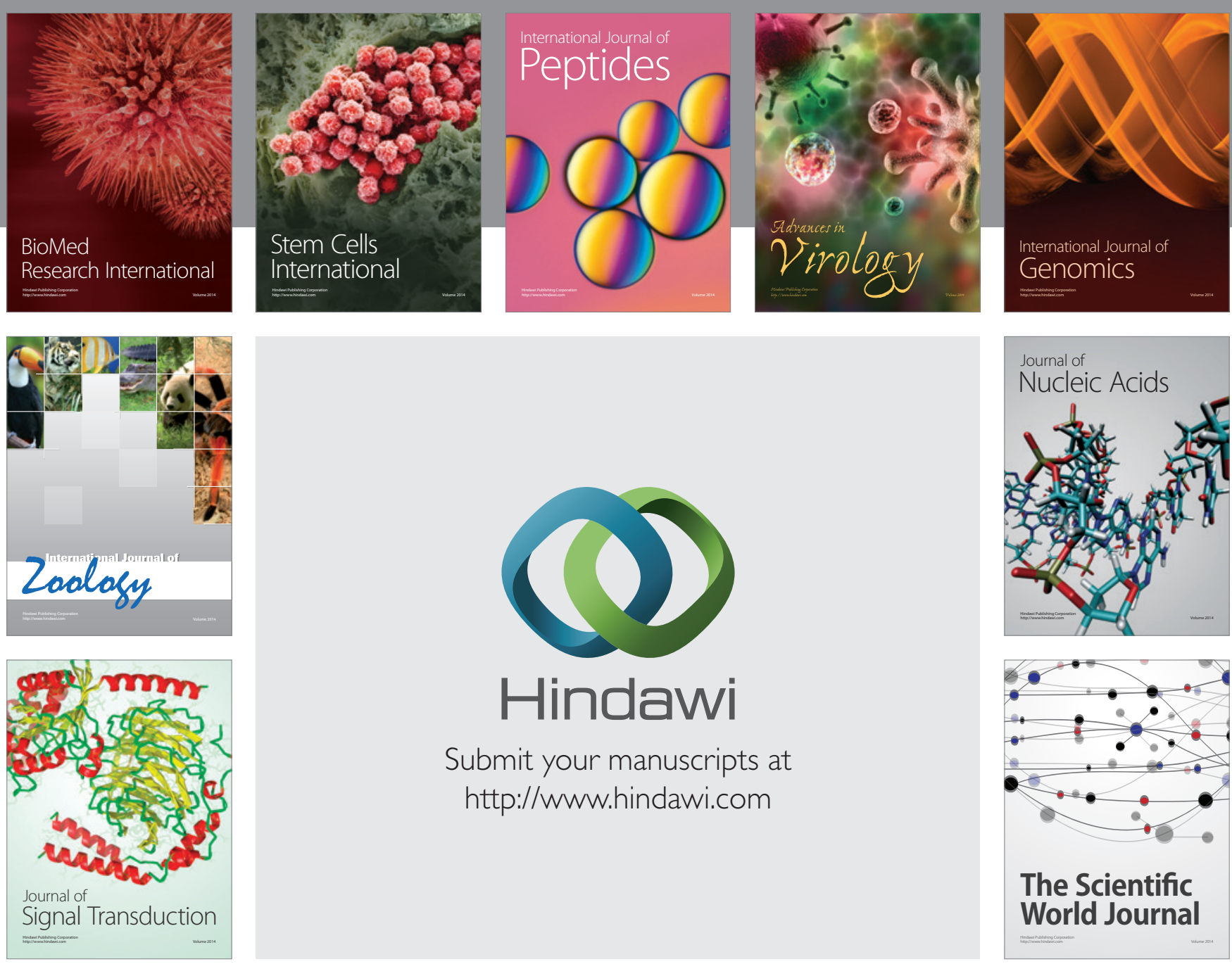

Submit your manuscripts at

http://www.hindawi.com
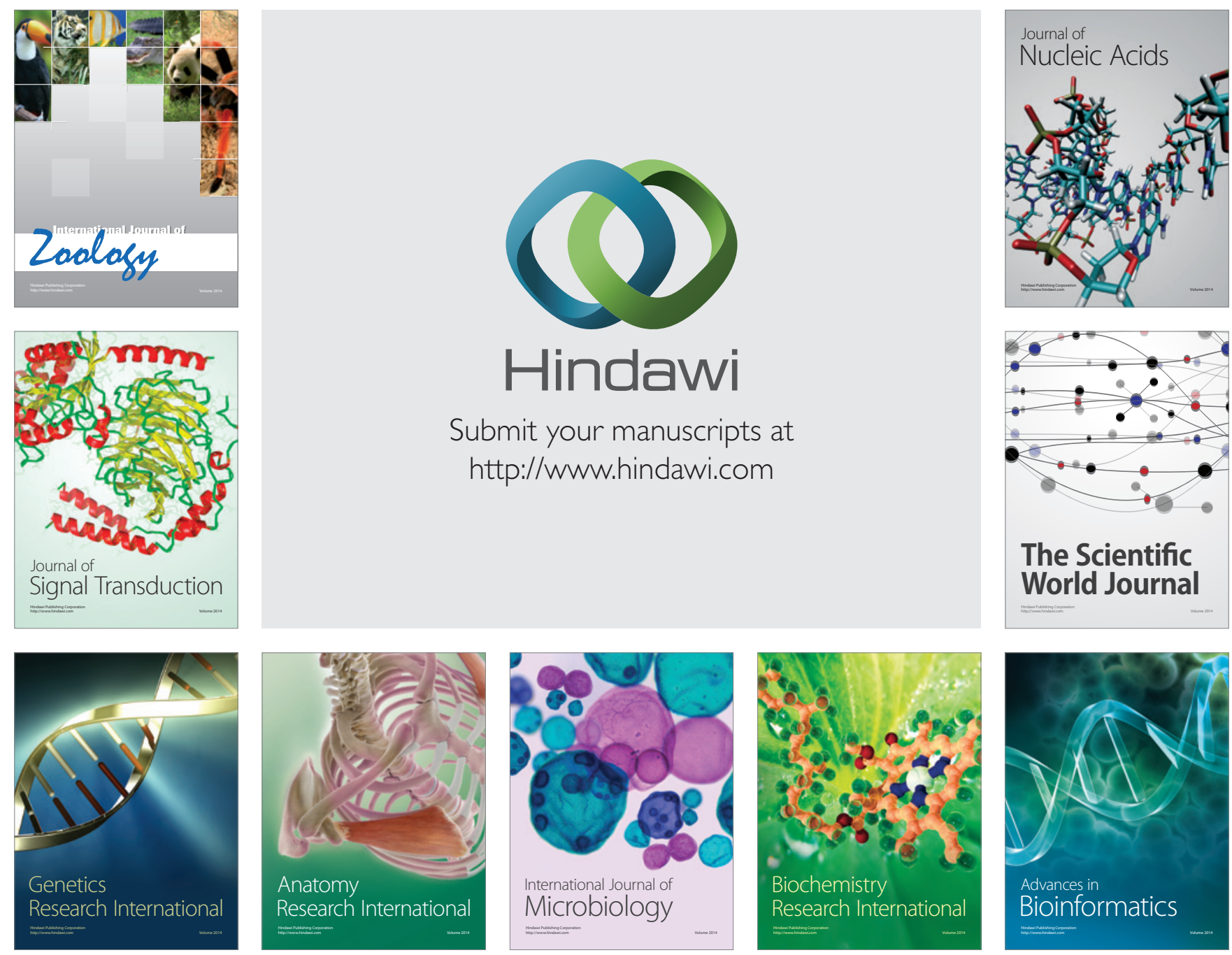

The Scientific World Journal
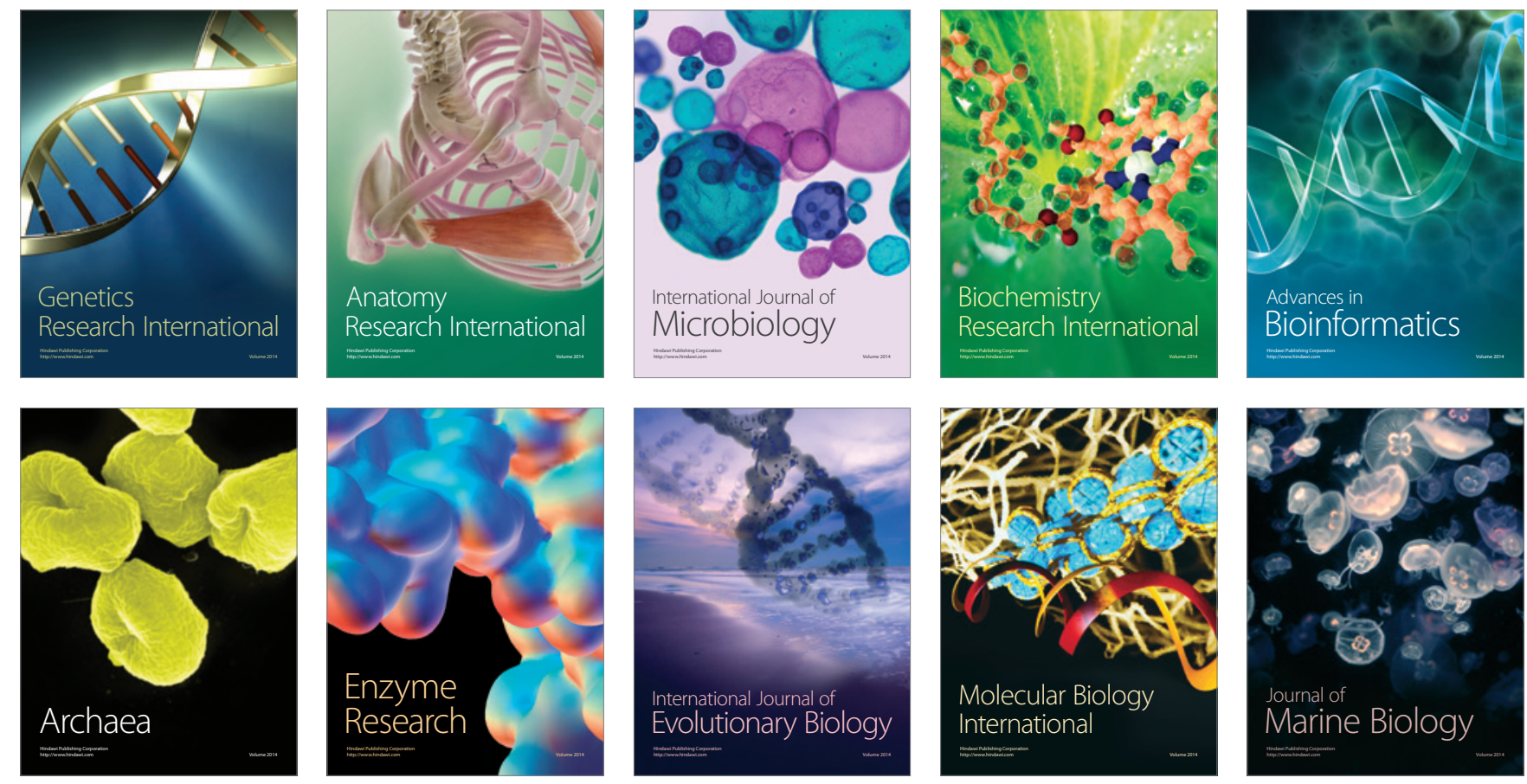